\title{
On Maximum Evaporation Rates of Liquid Droplets in Rocket Motors
}

\author{
S. S. $\mathbb{P E N N E R}{ }^{2}$
}

Daniel and Florence Guggenheim Jet Propulsion Center, California Institute of Technology, Pasadena, Calif.

Upper limits have been estimated for the rate of evaporation of small liquid droplets in representative rocket combustion chambers. The droplets are assumed to be isothermal at all times. The droplet temperature as a function of time is determined by an appropriate heat balance. The calculations are useful in determining the significance of inelastic collisions between liquid droplets for complete combustion. Radiant heat transfer to moving liquid droplets is considered briefly.

\section{Introduction}

$\mathbb{E}^{\mathrm{x}}$ XPERIMENTAL studies of liquid fuel rockets have shown that the performance of many bipropellant systems is dependent on the type of injection system employed. The results indicate the importance of $(a)$ the size of the liquid droplets at the point of injection, and $(b)$ the relative directions of injection of the separate streams of fuel and oxidant.

These experimental findings suggest a combustion mechanism in liquid fuel rockets which may be represented schematically as follows:

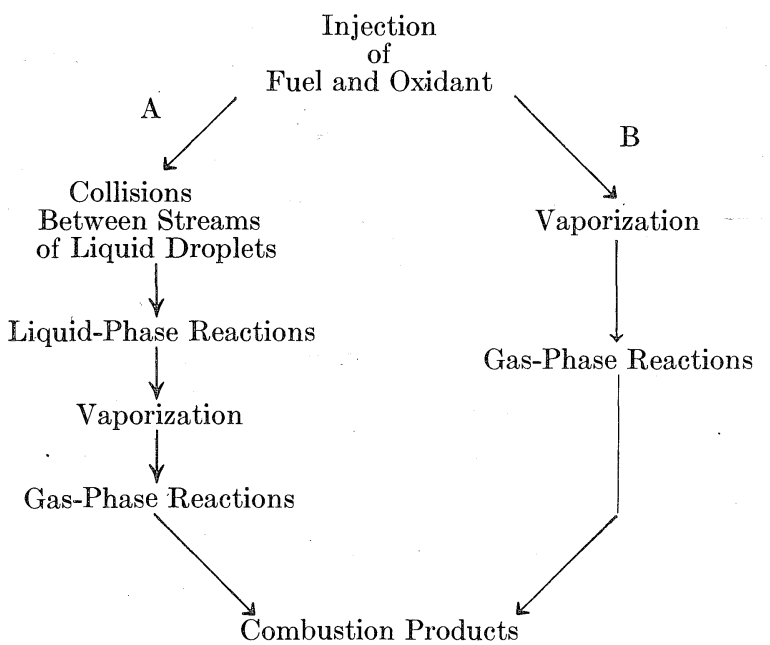

Mechanisms A and B generally occur concurrently in a motor chamber. For any given set of conditions, either mechanism $\mathrm{A}$ or mechanism $\mathrm{B}$ may be of greater importance.

An indication regarding the relative importance of mechanisms $\mathrm{A}$ and $\mathrm{B}$ may be obtained by determining whether liquid droplets are in a given motor chamber for a sufficiently long

Received July $14,1952$.

1 This paper presents the results of one phase of research carried out at the Jet Propulsion Laboratory, California Institute of Technology, under U. S. Army Ordnance Department Contract No. W-04-200-ORD-1482. The original manuscript was distributed as Progress Report No. 9-13 by the Jet Propulsion Laboratory in September 1947.

${ }^{2}$ Assistant Professor of Jet Propulsion. Formerly with Jet Propulsion Laboratory, California Institute of Technology, Pasadena Calif. period of time to vaporize completely without the occurrence of exothermic liquid-phase reactions. If the time required for the complete vaporization of the liquid droplets is greater than the time spent by the liquid droplets in the motor chamber, then liquid-phase reactions must occur, provided complete combustion takes place in the rocket chamber. It is therefore of interest to determine the minimum time required for the evaporation of liquid droplets in a rocket chamber. ${ }^{3}$

The evaporation of liquids and solids has been studied both experimentally and theoretically (1-11). ${ }^{4}$ Extended theoretical investigations of vaporization under idealized conditions have been carried out by Fuchs (5). A general treatment for the calculation of droplet lifetimes in combustion chambers has been described by Wentzel (6). Application of the results of these studies on evaporation to the special conditions existing in a rocket chamber cannot readily be made. The treatment of Wentzel (6), although applicable in principle, requires knowledge of a number of empirically determined parameters which are not generally available. Furthermore, there are indications that the usual laws which govern the evaporation of liquid droplets may not be valid for droplets of exceedingly small size. For example, Probert (1) indicates that the rate of evaporation of very small droplets is proportional to the diameter of the evaporating droplet rather than to the square of the diameter. Studies on comparatively large drops ( $0.5 \mathrm{~mm}$ in radius) (4) led to the conclusion that the treatment of Fuchs (5) for the rate of evaporation of drops is essentially correct. The work of Fuchs, in so far as it applies to very low Reynolds numbers, has been criticized recently (11). Finally, a study of evaporation rates for falling and burning droplets by Topps (12) shows a complicated dependence for evaporation rate on size and Reynolds number.

In view of the obvious complexity of the problem, no attempt was made to carry through a complete treatment of the rate of evaporation of liquid droplets in a rocket chamber. Instead, an approximate treatment has been employed which is designed to estimate a reasonable upper limit for the rate of droplet vaporization in a rocket chamber. A discussion of the maximum and minimum rates of evaporation, under conditions somewhat different from those of interest for the present study, has been given previously (13).

The results of the present investigation emphasize the importance of droplet size. For example, at least $1.58 \times 10^{-3}$ sec is required before the radius of an aniline droplet decreases. from $5 \times 10^{-3} \mathrm{~cm}$ to $2.5 \times 10^{-3} \mathrm{~cm}$. However, more than $1 \times 10^{-2}$ sec is required before an aniline droplet initially

\footnotetext{
${ }^{3}$ It should be noted particularly that the present investigation was undertaken with the modest objective of approximating minimum lifetimes of droplets rather than with the idea of obtaining a realistic estimate of the complicated evaporation processes involved in heterogeneous combustion. For recently published reports on heterogeneous combustion see, for example, J. E. C. Topps, J. Inst. Petrol., vol. 37, 535 (1951); G. A. E. Godsave, National Gas Turbine Establishment Reports Nos. R. 66, March 1950, and R. 87, April 1951, Pyestock, Hants, England; D. B. Spalding, Fuel, vol. 29, 2, 25, 1950; vol. 30, 121, 1951.

${ }^{4}$ Numbers in parentheses refer to References on page 88 .
} 
$1 \times 10^{-2} \mathrm{~cm}$ in diameter decreases to one half of its original diameter. The rate of evaporation is, of course, dependent on the nature of the evaporating compound. Thus octane is found to evaporate more rapidly than aniline under similar experimental conditions. The transfer of radiant energy to a moving liquid droplet is discussed. The analysis shows that the maximum possible temperature rise associated with the absorption of radiant energy increases as the droplet diameter is decreased.

\section{Outline of Theory}

The rate of droplet vaporization depends upon the nature of the evaporating liquid and upon the heat transferred to the liquid droplets after injection into the combustion chamber. The minimum life of a liquid droplet in a rocket chamber may be calculated by using an upper limit for the heat transfer and also for the isothermal rate of decrease of droplet radius with time.

The order of magnitude of the upper limit for the isothermal rate of decrease of droplet radius with time can be calculated from the Knudsen equation, which may be written in the form (14-16)

$$
-d r / d t=\left(p_{s} / \rho_{l}\right)(M / 2 \pi R T)^{(1 / 2)}
$$

where $r$ is radius of the evaporating droplet, $t$ time, $p_{s}$ saturated vapor pressure of the evaporating liquid at a given temperature, $\rho_{l}$ density of the evaporating liquid, $M$ molecular weight of the evaporating compound, $T$ temperature, $R$ gas constant. An upper limit for the heat transfer to the liquid droplets is obtained by maximizing the product $h \Delta T$ in the relation

$$
Q=4 \pi r^{2} h \Delta T .
$$

where $Q$ is rate of heat transfer to a spherical droplet of radius $r, h$ is over-all coefficient of heat transfer to a liquid droplet evaluated at the mean film temperature, $\Delta T$ is mean temperature difference between the gases surrounding the liquid droplet and the liquid droplet itself.

The order of magnitude of the value of $h$ may be ascertained from an empirical relation determined as the result of heat transfer studies between air and spheres (17, p. 237), ${ }^{5}$ viz.,

$$
\left(2 h r / k_{f}\right)=0.33\left(2 r G / \mu_{f}\right)^{0.6} \text {. }
$$

where $k_{f}$ is thermal conductivity of the hot gases at temperature $T_{f}, G=$ mass rate of flow of air past the liquid droplets, $\mu_{f}=$ viscosity of hot gases at the temperature $T_{f}, T_{f}=T+$ $0.5\left(T_{c}-T\right)$ where $T$ is the droplet temperature (assumed to be uniform), $T_{c}=$ temperature of the hot gases. At a chamber temperature of $3000^{\circ} \mathrm{K}$ and a pressure of $300 \mathrm{psi}$, it is found that Equation [3] leads to values of $2 h r / k_{f}$ of about 4 for the largest droplets $\left(r=10^{-2} \mathrm{~cm}\right.$ in radius), even if the droplets move at $100 \mathrm{fps}$ relative to the gases in the chamber. For very small droplets, on the other hand, $0.33\left(2 r G / \mu_{f}\right)^{0.6}<2$. However, the theoretical lower limit for $2 h r / k_{f}$ is 2 in a stagnant medium unless the spheres have diameters of the same order of magnitude as the mean free path in the fluid. Therefore, it is evident that $2 h r / k_{f}$ for small droplets does not differ greatly from 2 , and considering the fact that the gases at the head end of the rocket chamber move, on the average, in the direction of the droplets, ${ }^{6}$ it appears likely that even for $r=$ $10^{-2} \mathrm{~cm}$, the approximation $h=k_{f} / r$ will yield a reasonable estimate for heat transfer to the droplet. ${ }^{7}$ Thus we set

${ }^{5}$ It should be noted that the conclusion reached by using Equation [3] is the same as that obtained from the elegant treatment on heat transfer to spheres for very low Reynolds numbers given by Kronig and Bruijsten (11).

${ }^{6}$ Representative estimates of gas velocities near the injector are of the order of $50 \mathrm{fps}$.

${ }^{7}$ This last conclusion does not make allowance for the possible occurrence of turbulent motion near the injector.

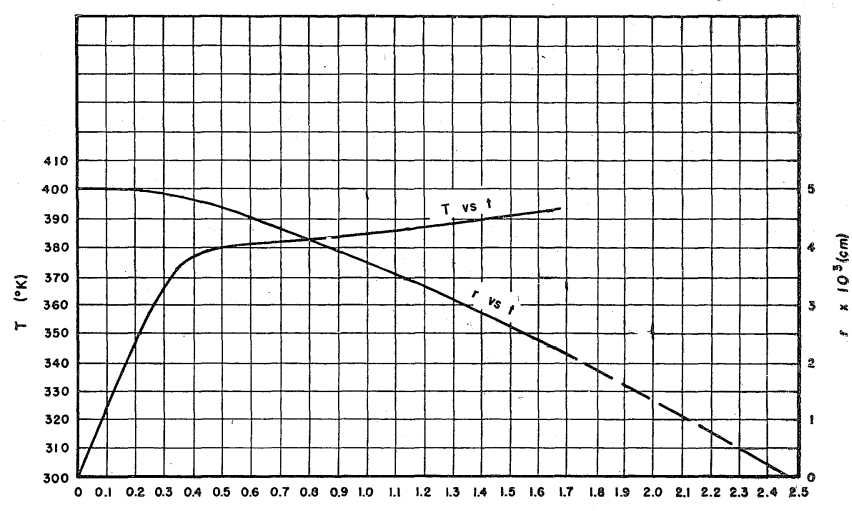

$1 \times 10^{3}(\mathrm{sec})$

FIG. 1 TEMPERATURE-VS.-TIME AND RADIUS-VS.-TIME DATA FOR AN ANILINE DROPLET IN A NITRIC-ACID-ANILINE ROCKET MOTOR $\left(T_{c}=3000^{\circ} \mathrm{K}, T_{0}=300^{\circ} \mathrm{K}, r_{0}=5 \times 10^{-3} \mathrm{CM}\right)$.

$$
\Delta T=3000-T \text { with } h=k_{f} / r_{0} \ldots \ldots \ldots[3 \mathrm{a}]
$$

The rate of temperature rise with time, $(d T / d t)_{1}$, of a spherical droplet receiving the energy $Q$ is

$$
(d T / d t)_{1}=Q\left(4 \pi r^{3} / 3\right)^{-1}\left(\rho_{l} C_{l}\right)^{-1}=3 h \Delta T / r \rho_{l} C_{l} \ldots
$$

where $C_{l}$ is the heat capacity per unit weight of the evaporating liquid. The liquid droplet is cooled as the result of evaporation. The rate of decrease of temperature with time associated with the cooling effect of evaporation is given according to the relation

$$
-(d T / d t)_{2}=\left(3 \Delta H_{\text {vap }} / C_{l} M r\right)(-d r / d t) \ldots
$$

where $\Delta H_{\text {vap }}$ is the heat of vaporization of the liquid per mole, and $(-d r / d t)$ is given by Equation [1]. The net rate of change of temperature with time is therefore

$$
d T / d t=\left(3 k_{f} \Delta T / r^{2} \rho_{l} C_{l}\right)-\left(3 \Delta H_{\mathrm{vap}} / r M C_{l}\right)(-d r / d t) .
$$

where use has been made of Equation [3a].

Reference to Equation. [6] indicates that the temperature of an evaporating liquid droplet changes continuously with time. Since the first term on the right-hand side of Equation [6] varies nearly inversely with the square of the radius, whereas the second term varies inversely as the first power of the radius, it is apparent that the droplet temperature will rise rapidly for very small droplets. For moderately large droplet sizes, Equation [6] is found to lead to quasi-steadystate temperatures.

\section{Calculation of Minimum Lifetimes of Droplets}

Equations [1] and [6] can be solved numerically without difficulty. A representative calculation is outlined below for the evaporation of aniline in a nitric-acid-aniline rocket operating at a chamber temperature of $3000^{\circ} \mathrm{K}$

The aniline droplets are chosen to have an initial diameter of $5 \times 10^{-3} \mathrm{~cm}$. They are injected at an initial temperature of $300^{\circ} \mathrm{K}$ with an average velocity of $100 \mathrm{fps}$ into a rocket chamber $1 \mathrm{ft}$ in length. The droplet velocity is assumed to remain constant. Thus the droplets remain in the rocket chamber for $0.01 \mathrm{sec}$. It is therefore of interest to determine the temperature and radius of the aniline droplets as a function of time for $0.01 \mathrm{sec}$.

The gaseous combustion products in the nitric-acid aniline rocket consist predominantly of $\mathrm{NO}, \mathrm{CO}, \mathrm{CO}_{2}, \mathrm{H}_{2} \mathrm{O}$, and $\mathrm{N}_{2}$. Approximate calculations for these components lead to a value for $\mu_{f}$ of about $0.157 \mathrm{lb} / \mathrm{hr}-\mathrm{ft}$ (p. 411 of Ref. 17) at the temperature $T_{f}=300+0.5(3000-300)=1650^{\circ} \mathrm{K}$. For the specified composition, it is found (p. 415 of Ref. 17) that $C_{p} \mu_{f} / k_{f} \simeq 0.76$. Since $C_{p} \simeq 0.50 \mathrm{Btu} / \mathrm{lb}-{ }^{\circ} \mathrm{F}$ (p. 406 of Ref. 


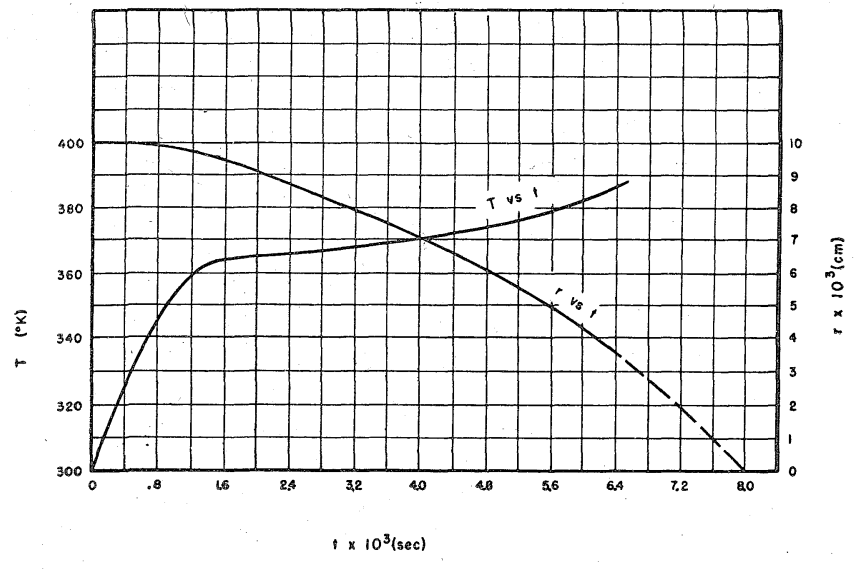

FIG. 2 TEMPERATURE-VS.-TIME AND RADIUS-VS.-TIME DATA FOR AN ANILINE DROPLET IN A NITRIC ACID-ANILINE ROCKET MOTOR $\left(T_{c}=3000^{\circ} \mathrm{K}, T_{0}=300^{\circ} \mathrm{K}, r_{0}=1 \times 10^{-2} \mathrm{CM}\right)$.

17), it follows that $k_{f} \simeq 0.104 \mathrm{Btu} / \mathrm{hr}^{-\mathrm{ft}-}{ }^{\circ} \mathrm{F}=4.30 \times 10^{-4}$ $\mathrm{cal} / \mathrm{sec}-\mathrm{cm}-{ }^{\circ} \mathrm{K}$.

For approximate calculations the numerical values of $k_{f}$, $\rho_{l}, C_{l}$, and $\Delta H_{\text {vap }}$ are assumed to be independent of temperature. Since the droplet temperature does not vary greatly with time, the error introduced by this simplification is not large. Thus, $T_{c}=3000^{\circ} \mathrm{K}, \rho_{l} \simeq 1.02 \mathrm{gm} / \mathrm{cm}^{3}, C_{l} \simeq$ $0.53 \mathrm{cal} / \mathrm{gm}-{ }^{\circ} \mathrm{C}, \quad M=93.12 \mathrm{gm} / \mathrm{mole}, \Delta H_{\mathrm{vap}} \simeq 12,000$ $\mathrm{cal} / \mathrm{mole}(18)$.

Introduction of the numerical values into Equation [6] leads to the desired result

$d T / d t=2.38 \times 10^{-3}\left[(3000-T) / r^{2}\right]-(730 / r)(-d r / d t) .[6 a]$

The values of $-d r / d t$ may be calculated directly from Equation [1] by use of measured values for the vapor pressure of aniline. For numerical work it is convenient to express $-d r / d t$, as a first approximation, by the relation $\log (-d r / d t) \simeq A-$ $B / T$, where $A$ and $B$ are nearly independent of temperature. For aniline it is found that

$$
\log (-d r / d t) \simeq 7.09-2.60 \times 10^{3} T^{-1} \ldots \ldots \ldots[7]
$$

Temperature-time and radius-time curves can be constructed from Equations [6a] and [7] by using a straightforward iteration procedure. Representative results for aniline, hydrazine, and octane are shown in Figs. 1 through 5 . The same numerical value for $k_{f}$ was employed for all of the calculations.

\section{Results}

The results plotted in Figs. 1 to 5, inclusive, exhibit the expected behavior. The temperature of the liquid droplets increases rapidly at first, then reaches a quasi-steady state, and finally rises very rapidly after the droplet radius has become sufficiently small. The droplet radius decreases continuously with time, very slowly at first, and then at an everincreasing rate as the droplet temperature rises. From Figs. 1 to 5 .it is possible to ascertain the minimum lifetimes of droplets for a number of different droplet sizes and liquids. The calculated results may be compared by evaluating the half life, $t_{(1 / 2)}$, of the liquid droplets, i.e., the time required to decrease the droplet diameters to one half of their original value. ${ }^{8}$ Relevant data are summarized in Table 1.

Reference to the results summarized in Table 1 shows that an aniline droplet with an initial radius of $1 \times 10^{-2} \mathrm{~cm}$.cannot evaporate in $0.01 \mathrm{sec}$ unless heat transfer to the liquid droplet is considerably greater than that calculated from

${ }^{8}$ The numerical value of $t(1 / 2)$ is always greater than one half the time required for complete evaporation of a given droplet. Calculation of the time required for complete evaporation is somewhat laborious.

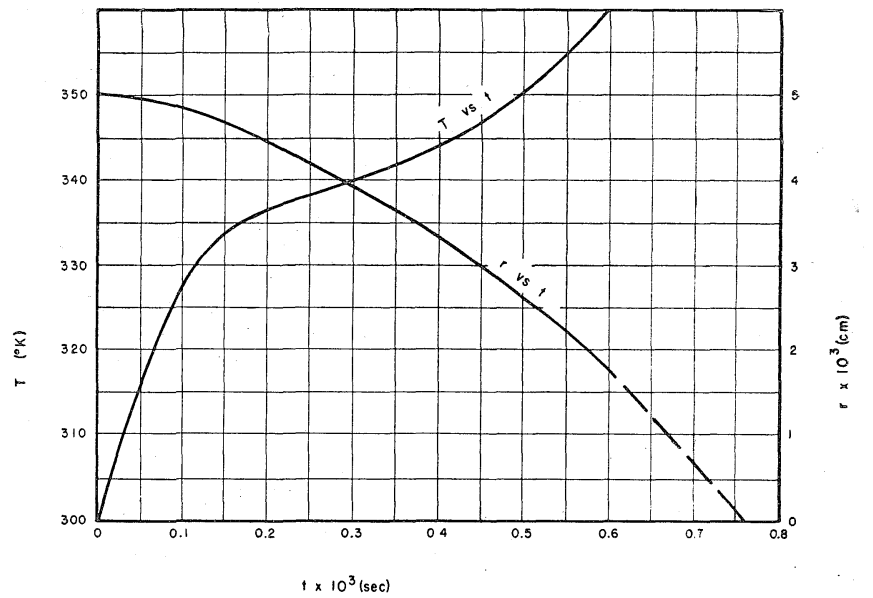

FIG. 3 TEMPERATURE-VS.-TIME AND RADIUS-VS.-TIME DATA FOR AN OCTANE DROPLET SURROUNDED BY HOT GASES AT $3000^{\circ} \mathrm{K}$ $\left(T_{0}=300^{\circ} \mathrm{K}, r_{0}=5 \times 10^{-3} \mathrm{CM}\right)$.

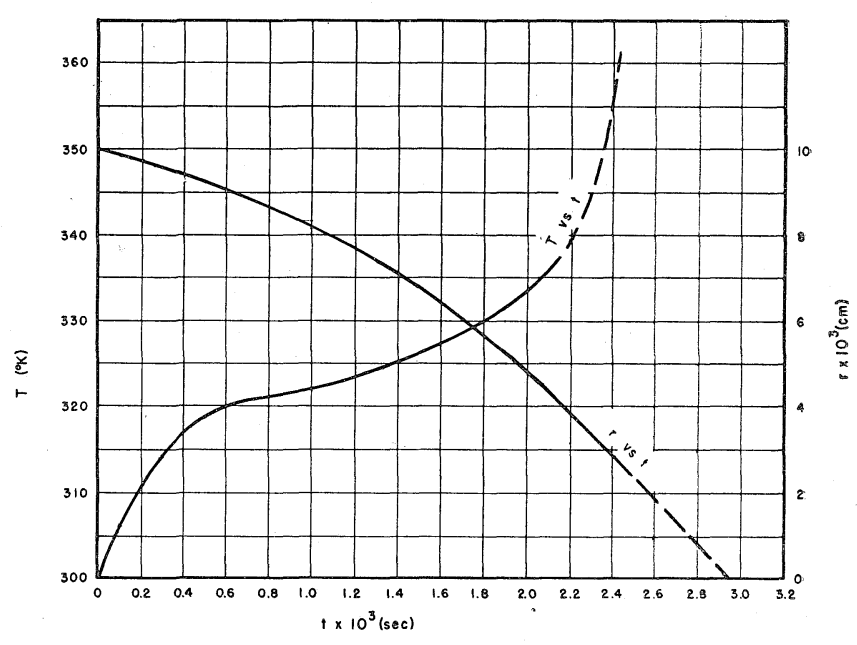

FIG. 4 TEMPERATURE-VS.-TIME AND RADIUS-VS.-TIME DATA FOR AN OCTANE DROPLET SURROUNDED BY HOT GASES AT $3000^{\circ} \mathrm{K}$ $\left(T_{0}=300^{\circ} \mathrm{K}, r_{0}=1 \times 10^{-2} \mathrm{CM}\right)$.

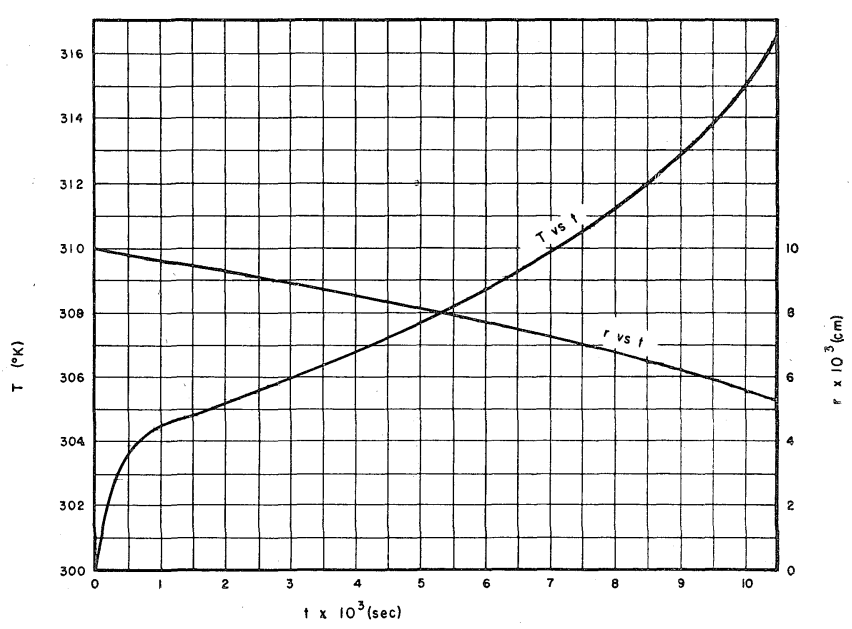

FIG. 5 TEMPERATURE-VS.-TIME AND RADIUS-VS.-TIME DATA FOR A HYDRAZINE DROPLET SURROUNDED BY HOT GASES AT $3000^{\circ} \mathrm{K}$ $\left(T_{0}=300^{\circ} \mathrm{K}, r_{0}=1 \times 10^{-2} \mathrm{CM}\right)$.

Equations [2] and [3]. Since only lower limits for the droplet lifetimes have been calculated, it is not possible to draw definite conclusions for the smaller droplet sizes for aniline. The evaporation of octane is seen to proceed more rapidly and at lower droplet temperatures than the evaporation of aniline. Hydrazine appears to evaporate somewhat more 
TABLE 1 MINIMUM HALF-LIFE OF LIQUID DROPLETS $\left(T_{c}=3000^{\circ} \mathrm{K}, T_{0}=300^{\circ} \mathrm{K}, h=k_{f} / r, k_{f}=4.3 \times 10^{-4} \mathrm{cal} / \mathrm{sec}-\right.$ $\mathrm{cm}-{ }^{\circ} \mathrm{K}$ )

$\begin{array}{lrcc}\text { Compound } & r_{0} \times 10^{3}(\mathrm{~cm}) & t^{a}(1 / 2) \times 10^{2}(\mathrm{sec}) & T_{(1 / 2)}^{b}\left({ }^{\circ} \mathrm{K}\right) \\ \text { Aniline } & 5 & 0.158 & 392 \\ \text { Octane } & 10 & 0.560 & 370 \\ & 5 & 0.052 & 352 \\ \text { Hydrazine } & 10 & 0.188 & 333 \\ & 10 & 1.07 & 317\end{array}$

${ }^{a} t_{(1 / 2)}=$ time required for the droplet diameter to decrease to one half of its original value.

${ }_{b} T_{(1 / 2)}=$ droplet temperature at $t_{(1 / 2)}$.

slowly than aniline. Because of the uncertainties which exist with regard to droplet size distribution in rocket motors, ${ }^{9}$ it is not possible at this time to draw definite conclusions with regard to the importance of liquid phase reactions in given rocket motors. However, it is evidently desirable to extend the calculations presented in this discussion to larger droplets by using the known size and velocity distributions in combustion chambers in conjunction with realistic heat transfer equations.

\section{Radiation Heating of Liquid Droplets}

Equations for the heat transfer by radiation to a liquid droplet moving along the axis of a rocket motor chamber have been derived previously (19). It was shown that the radiant energy, $I_{T}$, received per square centimeter of surface during the residence time $t_{r}$ in the rocket chamber, is given by the approximate relation

$$
\begin{aligned}
I_{T}=[2 / a(a+L)] \int_{\lambda} I_{\lambda}{ }_{\lambda} d \lambda \int_{0}^{t_{r}} d t\left\{\int _ { 0 } ^ { a } \left[1-\exp \left\{-k_{\lambda} \rho\left[\alpha^{2}+\right.\right.\right.\right. \\
\left.\left.\left.(L-v t)^{2}\right](1 / 2)\right\}\right] \alpha d \alpha+\int_{0}^{L-v t}\left\{1-\exp \left[-k_{\lambda} \rho\left(a^{2}+\right.\right.\right. \\
\left.\left.\left.\left.x^{2}\right)^{(1 / 2)}\right]\right\} a d x\right\} \ldots \ldots[8]
\end{aligned}
$$

where $a$ is radius of cylindrical motor chamber $(\mathrm{cm}) ; L$ length of chamber $(\mathrm{cm}) ; I^{\circ}{ }_{\lambda}$ radiant energy (cal $\left./ \mathrm{cm}^{2}-\mathrm{sec}\right)$ emitted by a blackbody radiator in the wave-length region between $\lambda$ and $\lambda+d \lambda$, the blackbody being at the same temperature as the radiating gases surrounding the moving liquid droplet; $t$ is time (sec); $t_{r}$ residence time of the liquid droplet in the motor chamber (sec); $\rho$ density of the hot radiating gases $\left(\mathrm{gm} / \mathrm{cm}^{3}\right) ; k_{\lambda}$ spectral mass absorptivity of the gases $\left(\mathrm{cm}^{2} / \mathrm{gm}\right) ; \quad v$ linear flow velocity of the moving liquid droplets $(\mathrm{cm} / \mathrm{sec})$.

Approximate calculations of heat transfer by radiation to moving liquid droplets have been carried out for the case where $a=7 \mathrm{~cm}, L=30 \mathrm{~cm}, T_{c}=3000^{\circ} \mathrm{K}, \mathcal{S} I^{\circ}{ }_{\lambda} d \lambda=115$ $\mathrm{cal} / \mathrm{cm}^{2}$-sec, $t_{r}=0.01 \mathrm{sec}, k_{\lambda}=40 \mathrm{~cm}^{2} / \mathrm{gm}, \rho=2 \times 10^{-3}$ $\mathrm{gm} / \mathrm{cm}^{3}, v=3 \times 10^{3} \mathrm{~cm} / \mathrm{sec}$. Evaluation of $I_{T}$ from Equation [8] for the specified numerical values leads to the result $I_{T}=0.733 \mathrm{cal} / \mathrm{cm}^{2}$. The maximum possible radiant energy, $I_{T}^{\prime}$, incident on a liquid droplet surrounded by blackbody radiators for $0.01 \mathrm{sec}$, is $I^{\prime}{ }_{T}=1.15 \mathrm{cal} / \mathrm{cm}^{2}$ if the blackbody radiators are at $3000^{\circ} \mathrm{K}$. This is only about 1.6 times the value calculated from Equation [8]. However, the calculated value of $I_{T}$ may not be significant, since the assumed value of $k \lambda=40 \mathrm{~cm}^{2} / \mathrm{gm}$ may be too high for a liquid fuel rocket operating at a pressure of $300 \mathrm{psi}$ (19).

The temperature rise $\Delta T$ of a spherical liquid droplet of radius $r$, caused by incident radiation $I_{T \lambda} \mathrm{cal} / \mathrm{cm}^{2}$ in the wavelength region between $\lambda$ and $\lambda+d \lambda$ is given by the relation (19)

$$
\Delta T_{R}=\left(3 / r C_{l} \rho_{l}\right) \int_{\lambda} I_{T_{\lambda}}\left[1-\exp \left(-2 K_{\lambda} r\right)\right] d \lambda \ldots \ldots
$$

${ }^{9}$ Dr. J. M. Schmidt, of JPL, CalTech, estimates the radius of aniline droplets at the point of injection into a nitric-acid-aniline rocket as probably lying between $5 \times 10^{-3}$ and $5 \times 10^{-2} \mathrm{~cm}$. Our analysis does not apply to the largest droplets. where $K_{\lambda}$ is the absorption coefficient (in $\mathrm{cm}^{-1}$ ) of the liquid droplet for light in the wave-length region between $\lambda$ and $\lambda+$ $d \lambda$. Evaluation of $\Delta T_{R}$ by use of Equation [9] can be performed only if $K_{\lambda}$ is known as a function of wave length. Experimental determination of $K_{\lambda}$ could be carried out in the same manner as was done previously for double-base rocket propellants (20).

If an average value $\bar{K}$ may be used for $K_{\lambda}$, then $\Delta T_{R}$ is given by the relation

$$
\Delta T_{R}=3 I_{T}[1-\exp (-2 \bar{K} r)]\left(r C_{l \rho_{l}}\right)^{-1} \ldots \ldots
$$

For very small droplets and weak absorbers $[1-\exp (-\overline{2} \bar{K} r)]$ $\simeq 2 \bar{K} r$. Therefore

$$
\Delta T_{R} \simeq 6 I_{T} \bar{K} / C_{l} \rho_{l}
$$

The radiation temperature rise of small droplets, which are not blackbody absorbers, is therefore approximately proportional to $\bar{K}$. An upper limit may be estimated for $\Delta T_{R}$ by treating the absorbing liquid droplet as a blackbody. In this case

$$
\Delta T_{R_{\max }}=3 I_{T} / r C_{l \rho_{l}} \simeq 2.2 r^{-1},{ }^{\circ} \mathrm{K} \ldots \ldots
$$

if $C_{l} \rho_{l} \simeq 1 \mathrm{cal} / \mathrm{cm}^{3}-{ }^{\circ} \mathrm{K}$, and $I_{T}=0.733 \mathrm{cal} / \mathrm{cm}^{2}$.

It can be seen from Equation [11a] that the maximum possible temperature rise of liquid droplets caused by the absorption of radiant energy increases as the droplet size decreases. If Equation [11a] holds, then $\Delta T_{R_{\max }} \simeq 300^{\circ} \mathrm{K}$ for $r=5 \times 10^{-2} \mathrm{~cm}$, and $\Delta T_{R_{\max }}-300^{\circ} \mathrm{K}$ for $r=5 \times 10^{-3}$ $\mathrm{cm}$. In order to evaluate the relative importance of radiant heat transfer, we may compare the coefficient $\Delta T_{R} / \dot{t}_{\tau}$ with $(d T / d t)_{1}$ as given by Equation [4]. For very small droplets it appears that the equilibrium transfer of radiant energy in a rocket motor is probably not very significant. However, the quantitative effects of chemiluminescent radiation may well be important and merit extensive further study.

\section{References}

1 "The Influence of Spray Particle Size and Distribution in the Combustion of Oil Droplets," by R. P. Probert, Philosophical Magazine, vol. 37, 1946, pp. 94-105.

2 "Experiments on the Rate of Evaporation of Small Spheres as a Method of Determining Diffusion Coefficients-The Diffusion Coefficient of Iodine," by B. Topley and R. W. WhytlawGray, Philosophical Magazine, vol. 4, 1927, pp. 873-888.

3 "A Study of the Evaporation of Small Water Droplets," by H. G. Houghton, Physics, vol. 4, 1933, pp. 419-424.

4 "The Rate of Evaporation of Droplets. Evaporation and Diffusion Coefficients and Vapor Pressures of Dibutyl Phthalate and Butyl Stearate," by R. S. Bradley, M. G. Evans, and R. W. Whytlaw-Gray, Proceedings of the Royal Society of London, vol. 186A, 1946, pp. 368-390.

5 "Rate of Evaporation of Small Droplets into a Gaseous Atmosphere," by N. Fuchs, Physikalische Zeitschrift der Sowjetunion, vol. 6, 1934, pp. 224-243.

6 "Ignition in a Diesel Motor," by W. Wentzel, Forschung auf dem Gebiete des Ingenieurwesens, vol. 6, 1935, pp. 105-115.

7 "Rates of Evaporation. IV. The Rate of Evaporation and Vapour Pressure of Rhombic Sulfur," by R. S. Bradley, Proceedings of the Royal Society of London, vol.205A, 1951, pp. 553-563.

8 "The Rate of Evaporation of Droplets. V. Evaporation Characteristics of Some Branched-Chain Hydrocarbons and a Straight-Chain Fluorocarbon," by R. S. Bradley and G. C. S. Waghorn, Proceedings of the Royal Society of London, vol. 206A, 1951, pp. 65-72.

9 "Vaporization of Small Sulfur Droplets," by H. F. Johnstone and D. K. Eads, Industrial and Engineering Chemistry, vol. 42, 1950, pp. 2293-2298.

(Continued on page 98) 


\section{GROVE \\ SELF-ACTUATED \\ COMTROLS AMD RECULATORS}

$$
\text { for }
$$

High pressure liquids and gases

\section{Pressure Reducing}

Back Pressure

Relief and By-Pass

Manual Valves

Special light weight units

for air-borne service.

Special materials for corrosive or low-temperature applications.

\section{GROVE COITROLS, IIIC.} 6529 Hollis Street

Emeryville

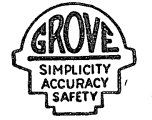

California

\section{Combustion Studies in Rocket Motors}

(Continued from page 96).

$60 \mathrm{deg}$, a given velocity change of the particle that could turn the velocity vector in the radiation record for $15 \mathrm{deg}$ in the upstream direction can only turn the velocity vector for $71 / 2$ deg in the downstream direction. While an upstream shock will almost cause flow reversal, a downstream shock of equal strength can hardly turn the velocity vector through 15 deg. In extreme cases, if the initial angle is as big as 80 $\mathrm{deg}$, a shock which is strong enough to cause flow reversal if moving upstream may hardly be discernible when it is moving downstream.

\section{References}

7 "High Frequency Combustion Instability in Rockets with Concentrated Combustion," by L. Crocco and S. I. Cheng, presented at the Eighth International Congress on Theoretical and Applied Mechanics, Istanbul, Turkey, August 1952 (to appear in a later issue of the Journal of the American Rocke't Societry).

8 "High Frequency Combustion Instability in Rockets with Distributed Combustion," by L. Crocco and S. I. Cheng, presented at the Fourth International Symposium on Combustion, Boston, Mass., September 1952.

\section{On Maximum Evaporation Rates of Liquid Droplets in Rocket Motors}

\section{(Continued from page 88)}

10 "Principles of Spray Drying. Part I: Fundamentals of Spray-Dryer Operation; Part II: Elements of Spray-Dryer Design," by W. R. Marshall, Jr., and E. Setzer, Chemical Engineering Progress, vol. 46, 1950, pp. 501-508, 575-584.

11 "On the Theory of the Heat and Mass Transfer from a Sphere in a Flowing Medium at Low Values of Reynolds Number," by R. Kronig and J. Bruijsten, Applied Science Research, vol. A2, 1951 , pp. $439-446$.

12 "An Experimental Study of the Evaporation and Combustion of Falling Droplets," by J. E. C. Topps, Journal of the Institute of Petroleum, vol. 37, 1951, pp. 535-553.

13 "An Analysis of the Factors Affecting the State of Fuel and Air Mixtures," by M. Gilbert, J. N. Howard, and B. L. Hicks, NACA Technical Note no. 1078, Washington, D. C., May 1946.

14 "Die Maximale Verdampfungs-geschwindigkeit des Quecksilbers," by M. Knudsen, Annalen der Physik, vol. 47, 1915, pp. $697-708$.

15 "On the Kinetics of Evaporation," by S. S. Penner, Journal of Physical Chemistry, vol. 56, 1952, pp. 475-479.

16 "Kinetic Theory of Gases," by E. H. Kennard, McGrawHill Book Co., Inc., New York, N. Y., 1938.

17 "Heat Transmission," by W. H. McAdams, McGraw-Hill Book Co., Inc., New York, N. Y., 1942.

18 "The Apparent Energy of the $\mathrm{N}-\mathrm{N}$ Bond as Calculated from Heats of Combustion," by C. M. Anderson and E. C. Gilbert, Journal of the American Chemical Society, vol. 64, 1942, pp. 2369-2372.

19 "Some Considerations of the Effect of Radiation on the Performance of Liquid Fuel Rockets," by S. S. Penner and S. Weinbaum, Journal of the Optical Society of America, vol. 38, 1948 , pp. 599-603, 840.

20 "Mass Emissivity of Powder Gases in Solid Fuel Rockets," by S. S. Penner, Journal of Applied Physics, vol. 19, 1948, pp. 278-285; "Effect of Radiation on the Rate of Burning of Solid Fuel Rocket Propellants," by S., S. Penner, Journal of Applied Physics, vol. 19, 1948, pp. 392-398; "Qualitative Experimental Verification of the Change of Burning Rate of Rocket Powders with Radiation Path Length," by S. S. Penner, Journal of A pplied Physics, vol. 19, 1948, pp. 511-513. See also "Studies of Radiation Phenomena in Rockets," by J. Beek, Jr., W. H. Avery, M. J. Dresher, F. T. McClure, and S. S. Penner, ABL Final Report P-2, OSRD Report No. 5817, June 1946. 